\title{
Effects of Nogo-A and its receptor on the repair of sciatic nerve injury in rats
}

\author{
Junjie Jiang ${ }^{1 \oplus 凶}$, Yuanchen $\mathrm{Yu}^{2 \oplus}$, Zhiwu Zhang ${ }^{1 \oplus}$, Yuan $\mathrm{Ji}^{1 \oplus}$, Hong Guo ${ }^{3 \oplus}$ \\ Xiaohua Wang ${ }^{2 \oplus}$, and Shengjun $\mathrm{Yu}^{1 \oplus}$ \\ ${ }^{1}$ Department of Hand Surgery, Yantaishan Hospital, Yantai, China \\ ${ }^{2}$ Department of Clinical Laboratory, Yantaishan Hospital, Yantai, China \\ ${ }^{3}$ Yantai City Municipal Government Hospital, Yantai, China
}

\begin{abstract}
Regeneration of injured peripheral nerves is an extremely complex process. Nogo-A (neurite outgrowth inhibitor-A) inhibits axonal regeneration by interacting with Nogo receptor in the myelin sheath of the central nervous system (CNS). The aim of this study was to investigate the effects of Nogo-A and its receptor on the repair of sciatic nerve injury in rats. Sprague-Dawley rats $(n=96)$ were randomly divided into 4 groups: control group (control), sciatic nerve transection group (model), immediate repair group (immediate repair), and delayed repair group (delayed repair). The rats were euthanized 1 week and 6 weeks after operation. The injured end tissues of the spinal cord and sciatic nerve were obtained. The protein expressions of Nogo-A and Nogo-66 receptor (NgR) were detected by immunohistochemistry. The protein expressions of Nogo-A, NgR, and Ras homolog family member A (RhoA) were detected by western blot. At 1 week after operation, the pathological changes in the immediate repaired group were less, and the protein expressions of Nogo-A, NgR, and RhoA in the spinal cord and sciatic nerve tissues were decreased $(P<0.05)$ compared with the model group. After 6 weeks, the pathological changes in the immediate repair group and the delayed repair group were alleviated and the protein expressions decreased $(P<0.05)$. The situation of the immediate repair group was better than that of the delayed repair group. Our data suggest that the expression of Nogo-A and its receptor increased after sciatic nerve injury, indicating that Nogo-A and its receptor play an inhibitory role in the repair process of sciatic nerve injury in rats.
\end{abstract}

Key words: Neurite outgrowth inhibitor-A; NgR; Sciatic nerve transection; Spinal cord

\section{Introduction}

In recent years, although central sensitization has been reported under recognized neuropathic conditions, there is a lack of information on the acute brain activation pattern of peripheral nerve injury (1). Neuropathic pain is still a major global health problem. Peripheral nerve injury is a common clinical disease that causes the partial loss of segmental movement and sensory and autonomic nervous function, placing a heavy burden on patients and their families (2). Therefore, increased attention has been paid to the treatment of sciatic nerve injury. The injury of sciatic nerve is related to the change of gene expression level (3). However, the role of these up-regulated or downregulated genes remains unclear. Understanding the molecular mechanism of the occurrence and development of sciatic nerve injury is a prerequisite for the development of effective treatment for this highly prevalent disease.

Currently, the repair and regeneration technology of injured peripheral nerve has been significantly improved $(4,5)$. Nogo-A (neurite outgrowth inhibitor-A) is a member of the reticulin protein family and exists in neurons and oligodendrocytes (6). Nogo-A inhibits axonal regeneration by interacting with Nogo receptor $(\mathrm{NgR})$ in the myelin sheath of the central nervous system (CNS) $(7,8)$. However, the function of Nogo-A in neurons remains unclear. As the main receptor of Nogo-A, NgR mediates its effects on Ras homolog family member $A(R h o A)$ and downstream pathways, resulting in collapse of growth cone and inhibition of oligodendrocyte differentiation (9-11).

Previous studies have shown that neutralizing Nogo-A inhibition can improve the functional recovery after spinal cord injury (12). Nogo-A activation of RhoA has also been shown to be important during cerebral infarction (13). The whole effect of hyperbaric oxygen can reduce the expression of Nogo-A and its pathway, and help to inhibit the immediate regeneration after global cerebral ischemia $(14,15)$. However, there is no information about the effect of Nogo-A, NgR, and RhoA on sciatic nerve recovery after injury.

Correspondence: Junjie Jiang: <JunjieJiang235@yeah.net> 
Therefore, the aim of this study was to investigate the effects of Nogo-A and its receptor on the repair of sciatic nerve injury in rats.

\section{Materials and Methods}

\section{Animals}

Eight-week-old male Sprague-Dawley rats $(180 \pm 20 \mathrm{~g})$ were purchased from Jinan Pengyue Experimental Animal Co., Ltd. (SCXK (Lu) 20190003, China). All rats were maintained at the standard conditions of temperature range $\left(23 \pm 2^{\circ} \mathrm{C}\right)$, average humidity $(55 \pm 5 \%)$, light-and-dark cycle of $12 \mathrm{~h}$, and eating and drinking ad libitum. Animal experiments followed the NIH guidelines (NIH pub. No. 85-23, revised 1996) and have been approved by the Yantaishan hospital animal protection and use committee (2018-14).

\section{Establishment of sciatic nerve injury model in rats}

The rats were anesthetized by intraperitoneal injection of $3 \%$ pentobarbital sodium $(50 \mathrm{mg} / \mathrm{kg}$ ). The skin was disinfected with $2 \%$ iodine tincture, and deiodinated by $75 \%$ alcohol. The incision from the left hip to the back of the thigh was about $5 \mathrm{~cm}$ long. After skin incision, the sciatic nerve was separated and exposed the anterior muscle space of biceps femoris. If necessary, some superficial gluteal muscles were cut off to expose the proximal end of the sciatic nerve to the piriformis outlet and the distal end to the middle and lower $1 / 3$ of the thigh. Sciatic nerve was cut off at $0.8 \mathrm{~cm}$ from piriformis muscle outlet. A sharp blade was used to cut the sciatic nerve once to avoid saw contusion. After operation, the wound was washed with sterile normal saline and the skin was sutured.

\section{Animal groups}

Ninety-six rats were randomly divided into 4 groups $(n=24): 1)$ control group: only the sciatic nerve was exposed without injury; 2) sciatic nerve transection group (model): $1 \mathrm{~cm}$ of sciatic nerve was removed at $0.8 \mathrm{~cm}$ from piriformis muscle outlet to simulate long nerve defect; 3) immediate repair group: the sciatic nerve was cut off at $0.8 \mathrm{~cm}$ from the piriformis outlet, and then the epineurium was sutured with $10 / 0$ non-invasive suture under the operating microscope to repair the severed sciatic nerve; and 4) delayed repair group: the sciatic nerve was cut off $0.8 \mathrm{~cm}$ at the exit of piriformis muscle, and the distance between the two cut ends was more than $1 \mathrm{~cm}$. After 32 days, the epineurium was sutured with 10/0 non-invasive suture under the operating microscope to repair the severed sciatic nerve.

\section{Samples collection}

At 1 week and 6 weeks after injury (or operation), 12 rats in each group were selected. Six rats were euthanized using $1 \%$ pentobarbital sodium (150 mg/kg). The injured end tissues of the spinal cord and sciatic nerve of the corresponding segments were placed in an Eppendorf tube and frozen in liquid nitrogen for western blot detection. The other 6 rats were perfused with normal saline and $4 \%$ paraformaldehyde through the left ventricle to the ascending aorta, and tissues of injured spinal cord and sciatic nerve were obtained, fixed with $4 \%$ paraformaldehyde for $24 \mathrm{~h}$, and paraffin embedded for histopathological and immunohistochemical detection.

\section{H\&E staining}

The thickness of paraffin sections was $5 \mu \mathrm{M}$. The slices were dewaxed with xylene and hydrated with ethanol. Sections were dyed with hematoxylin (Solarbio, China) for $5 \mathrm{~min}$ and washed with tap water. After $30 \mathrm{~s}$ of ethanol differentiation with hydrochloric acid, the sections were soaked in tap water for $15 \mathrm{~min}$, and then placed in eosin dye (Solarbio) for $2 \mathrm{~min}$. The tissues were observed under an Olympus optical microscope (BX51, Olympus, Japan) and histomorphological analysis was performed.

\section{Tissue immunohistochemistry staining}

Tissues were embedded in paraffin and sectioned, and then dewaxed with xylene and hydrated with gradient ethanol solution. $\mathrm{H}_{2} \mathrm{O}_{2}$ methanol solution (3\%) was added for inactivation treatment for $20 \mathrm{~min}$, high temperature antigen in citrate buffer solution $(\mathrm{pH} \mathrm{6.0)}$ was used for thermal repair for $10 \mathrm{~min}$, and $5 \%$ BSA was used for blocking treatment for $20 \mathrm{~min}$. Rabbit anti rat Nogo-A (1:200, orb337377, Biorbyt, UK) and NgR (1:500, orb185 998, Biorbyt) polyclonal antibodies were added and reacted overnight at $4^{\circ} \mathrm{C}$. After rewarming, goat anti-rabbit IgG labeled with horseradish peroxidase (1:1000, orb21465, Biorbyt, UK) was incubated with the secondary antibody. After DAB staining, slides were dyed again, then dehydrated, cleared, and finally sealed. The slides were observed under the optical microscope (400×, Olympus). Analysis was done with ImageJ software (NIH, USA), and the results are reported as the percentage of positive cells (\%).

\section{Western blotting}

Tissue samples were dispersed mechanically and centrifuged $\left(12,000 \mathrm{~g}, 10 \mathrm{~min}, 4^{\circ} \mathrm{C}\right)$. Then, the supernatant was collected, and the concentration of the supernatant was detected by a BCA kit (Solarbio). The $40-\mu \mathrm{g}$ protein sample was mixed with $10 \%$ SDS gel loading buffer (1:1), and heated at $95^{\circ} \mathrm{C}$ for $5 \mathrm{~min}$ to denature the protein. The samples were transferred to PVDF (Merck, Germany) for $30 \mathrm{~min}$ at $80 \mathrm{~V}$, and sealed with tris-buffered saline plus Tween 20 (TBST) solution containing 5\% skimmed milk powder for $1 \mathrm{~h}$ at $4^{\circ} \mathrm{C}$. Nogo-A, NgR, and RhoA were diluted with TBST solution containing $3 \%$ bovine serum protein, and polyclonal antibody of $\beta$-actin was reacted overnight at $4^{\circ} \mathrm{C}$. All antibodies used are listed in Table 1 . After rewarming, goat anti-rabbit IgG labeled with horseradish peroxidase (HRP) was incubated for $1 \mathrm{~h}$ at room temperature, washed, and stained with ECL luminescent substrate for $5 \mathrm{~min}$. The protein expression level was standardized by $\beta$-actin, and scanned and quantified by ImageJ software (USA). 


\section{Data analysis}

SPSS 19.0 software (IBM, USA) was used for data processing. The data are reported as means \pm SD. One-way analysis of variance (ANOVA) was used to compare the data between groups, and LSD test was used for post hoc analysis. All data were analyzed using Shapiro-Wilk normality test. $P<0.05$ was considered to be statistically significant.

\section{Results}

\section{H\&E staining}

As shown in Figure $1 \mathrm{~A}$, there was no inflammatory cell infiltration at each time point in the control group, and the

Table 1. Antibodies used in this study.

\begin{tabular}{lllc}
\hline Antibody & Source & Dilutions & Company \\
\hline$\beta$-actin & Rabbit & $1: 2000$ & orb178392, Biorbyt, UK \\
Nogo-A & Rabbit & $1: 1000$ & orb337377, Biorbyt, UK \\
NgR & Rabbit & $1: 500$ & orb285998, Biorbyt, UK \\
RhoA & Rabbit & $1: 500$ & orb228210, Biorbyt, UK \\
lgG & Rabbit & $1: 1000$ & orb21465, Biorbyt, UK \\
\hline
\end{tabular}

nerve fibers were arranged orderly, the tissue was dense, and the axon and myelin sheath had good continuity. One week after operation, the nerve fibers in the sciatic nerve transection group were disorderly arranged, some axons disappeared, vacuolar degeneration appeared, most of myelin sheath disintegrated, and edema and inflammatory cell infiltration could be seen. In the immediate sciatic nerve repair group, tissue fibers proliferated and the tissues showed signs of recovery. At 6 weeks after operation, the condition of all operation groups was improved. The pathological improvement of the immediate repair group was better than the delayed repair group. As shown in Figure 1B, one week after operation, there were more normal neurons in the posterior and anterior horn of the spinal cord in the sham operation group, with normal structure. The axons, dendrites, and nuclei of neurons were clear, and the nucleoli were located in the center. In the model group and delayed repair group, there was extensive vacuolation, necrosis, and pyknosis of neurons in the posterior and anterior horn of the spinal cord. The histological changes of spinal cord in the immediate repair group were less than those in the model group. At 6 weeks after operation, the number of normal neurons in the posterior and anterior horn of the spinal cord
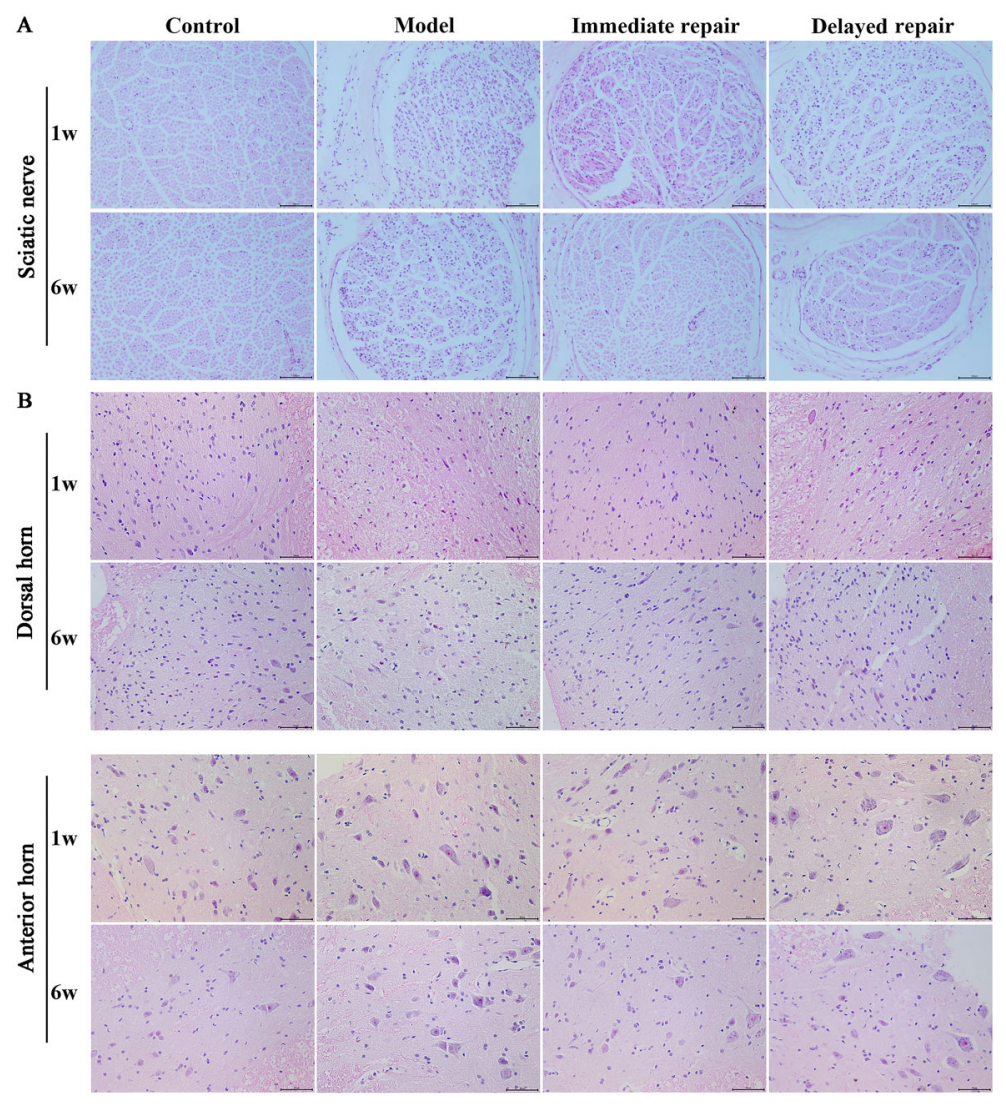

Figure 1. H\&E staining was used to observe the pathological changes of the sciatic nerve (A) and spinal cord (B) after sciatic nerve injury in rats of different groups. Panel A, magnification 200×; scale bar $100 \mu \mathrm{m}$; panel B, magnification $400 \times$; scale bar $50 \mu \mathrm{m}$. 

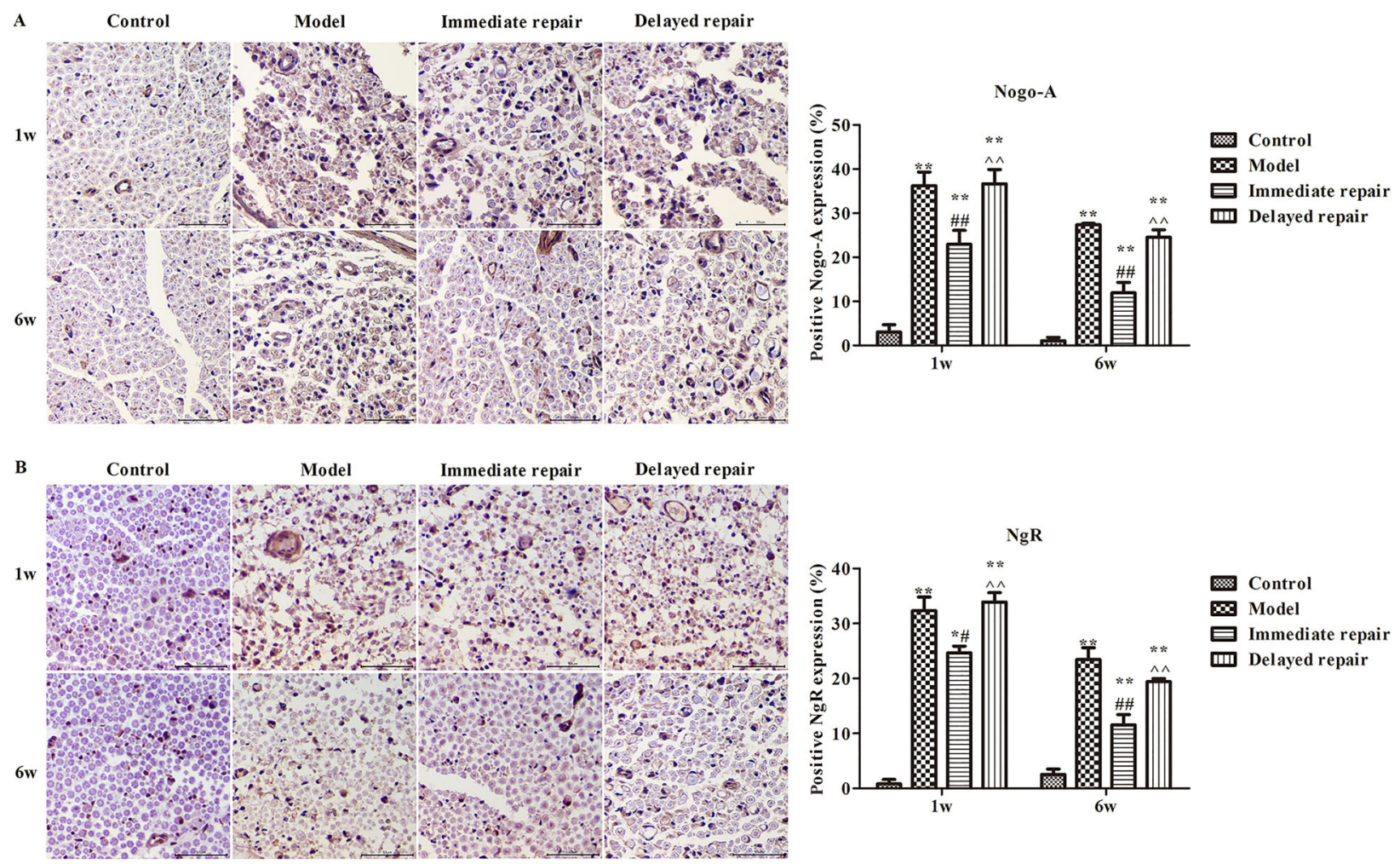

Figure 2. The expressions of Nogo-A (A) and $\mathrm{NgR}(\mathrm{B})$ were detected in sciatic nerve after sciatic nerve injury in rats of different groups by immunohistochemistry. Magnification $400 \times$, scale bar $50 \mu \mathrm{m}$. The data are reported as means $\pm S D$. ${ }^{*} P<0.05$, ${ }^{* *} P<0.01$ compared with control group; ${ }^{\#} \mathrm{P}<0.05,{ }^{\# \#} \mathrm{P}<0.01$ compared with model group; ${ }^{\wedge} \mathrm{P}<0.01$ compared with immediate repair group (ANOVA followed by LSD test).

increased in the model group and the delayed repair group, and neuronal necrosis and nuclear pyknosis were improved. In the immediate repair group, the motoneurons were preserved to a greater extent, and the degree of spinal cord injury was less.

\section{Protein expressions of Nogo-A and NgR in sciatic nerve}

Compared with the control group, the protein expressions of Nogo-A (Figure 2A) and $\mathrm{NgR}$ (Figure 2B) in sciatic nerve in the other three groups were significantly increased after 1 week and 6 weeks from operation. Compared with the model group, the protein expressions of Nogo-A and $\mathrm{NgR}$ in the immediate repair group were significantly decreased $(P<0.05)$.

Protein expressions of Nogo-A and $\mathrm{NgR}$ in spinal cord

As shown in Figure 3, at 1 week and 6 weeks after operation, the protein expressions of Nogo-A (Figure $3 A$ ) and $\mathrm{NgR}$ (Figure $3 \mathrm{~B}$ ) in the spinal cord were significantly increased in the other three groups compared with the control group both in dorsal horn and anterior horn $(P<0.05)$. Similar to the sciatic nerve, the expressions of Nogo-A and $\mathrm{NgR}$ in the immediate repair group were significantly decreased compared with the model group, and the immediate repair group was lower than that in the delayed repair group $(P<0.05)$.

\section{Protein expressions of Nogo-A, NgR, and RhoA}

As shown in Figure 4, 1 week after injury, compared with the control group, the protein expressions of Nogo-A (Figure 4A), NgR (Figure 4B), and RhoA (Figure 4C) in spinal cord and sciatic nerve tissues of the other three groups were significantly increased $(P<0.05)$. Compared with the model group, the expressions of Nogo-A, NgR, and RhoA proteins in the immediate repair group was significantly decreased $(P<0.05)$. After 6 weeks from injury, compared with the control group, the protein expressions of Nogo-A, $\mathrm{NgR}$, and RhoA in the other three groups were higher $(P<0.05)$. Compared with the model group, the protein expressions of Nogo-A, NgR, and RhoA in the immediate repair group and the delayed repair group were significantly decreased, and the protein expressions of Nogo-A, NgR, and RhoA in the immediate repair group were lower than those in the delayed repair group $(P<0.05)$. 

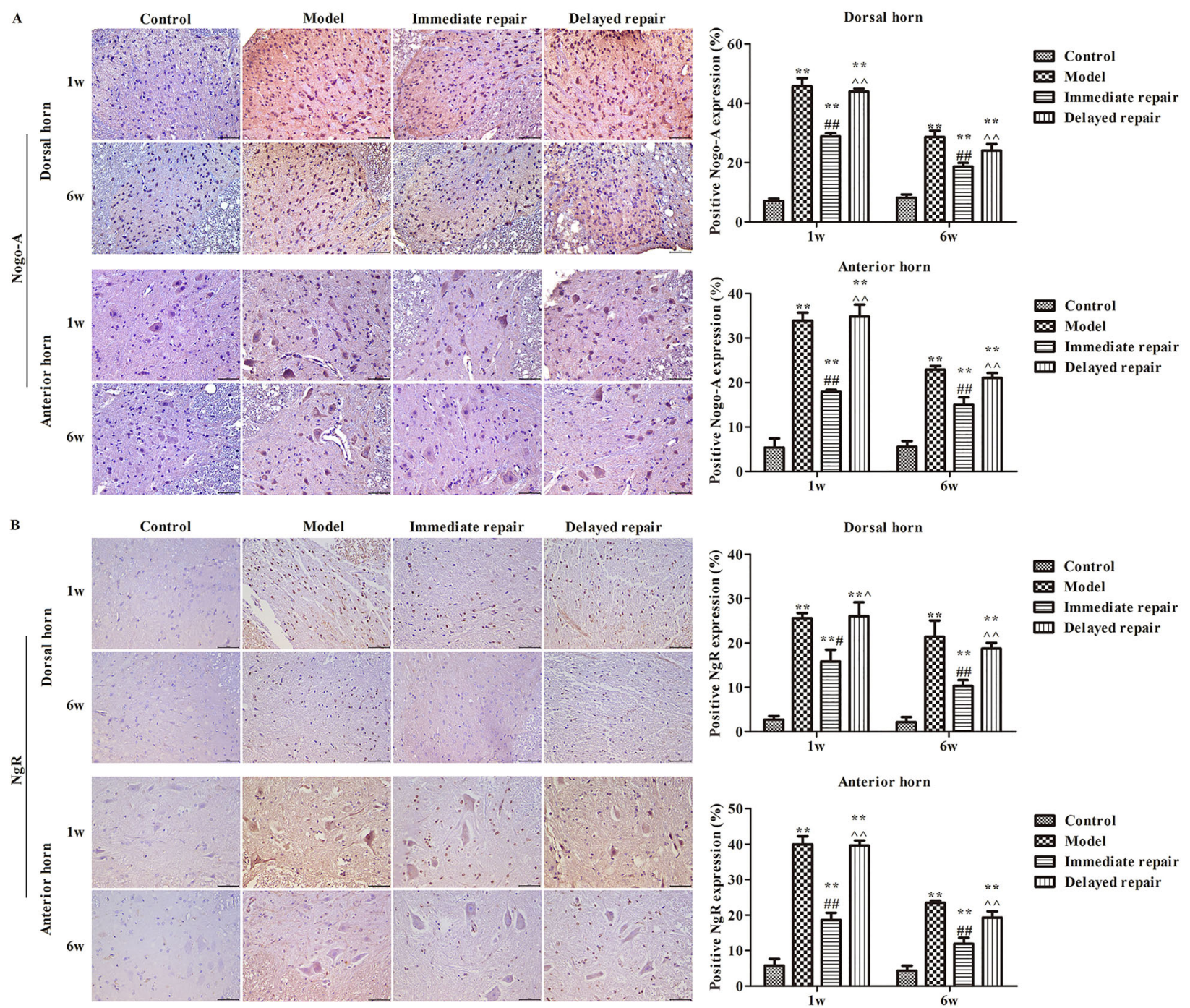

Figure 3. The expression of Nogo-A (A) and $\mathrm{NgR}(\mathbf{B})$ in the anterior horn and posterior horn of the spinal cord after sciatic nerve injury in rats of different groups was detected by immunohistochemistry. Magnification $400 \times$, scale bar $50 \mu \mathrm{m}$. The data are reported as means \pm $\mathrm{SD}$. ${ }^{\star *} \mathrm{P}<0.01$, compared with control group; ${ }^{\#} \mathrm{P}<0.05$, ${ }^{\# \#} \mathrm{P}<0.01$ compared with model group; ${ }^{\wedge} \mathrm{P}<0.05$, ${ }^{\wedge} \mathrm{P}<0.01$ compared to immediate repair group (ANOVA followed by LSD test).

\section{Discussion}

Nerve regeneration is a complex biological process, including a variety of cells, growth factors, and extracellular matrix. Elucidating the molecular mechanism of peripheral nerve injury and nerve repair can greatly improve the therapeutic strategies of the disease $(16,17)$. Therefore, the search for the key genes that activate the intrinsic growth ability of neurons is important for the field. Peripheral neuropathy of the lower extremity is a common condition, usually associated with trauma and surgery $(18,19)$. These injuries seriously affect the activity and function of patients, and are closely related to social and economic problems.

Previous studies have demonstrated the expression of Nogo-A in peripheral sensory neurons, the increase of Nogo-A mRNA or protein in hippocampal pyramidal neurons after injury of the inner olfactory cortex, and the increase of Nogo-A mRNA or protein in neurons after middle cerebral artery occlusion (20-22). In our study, the expression of Nogo-A protein in the spinal cord and sciatic nerve tissues increased after sciatic nerve transection. Compared with the sciatic nerve transection group, the pathological changes in the immediately repaired sciatic 

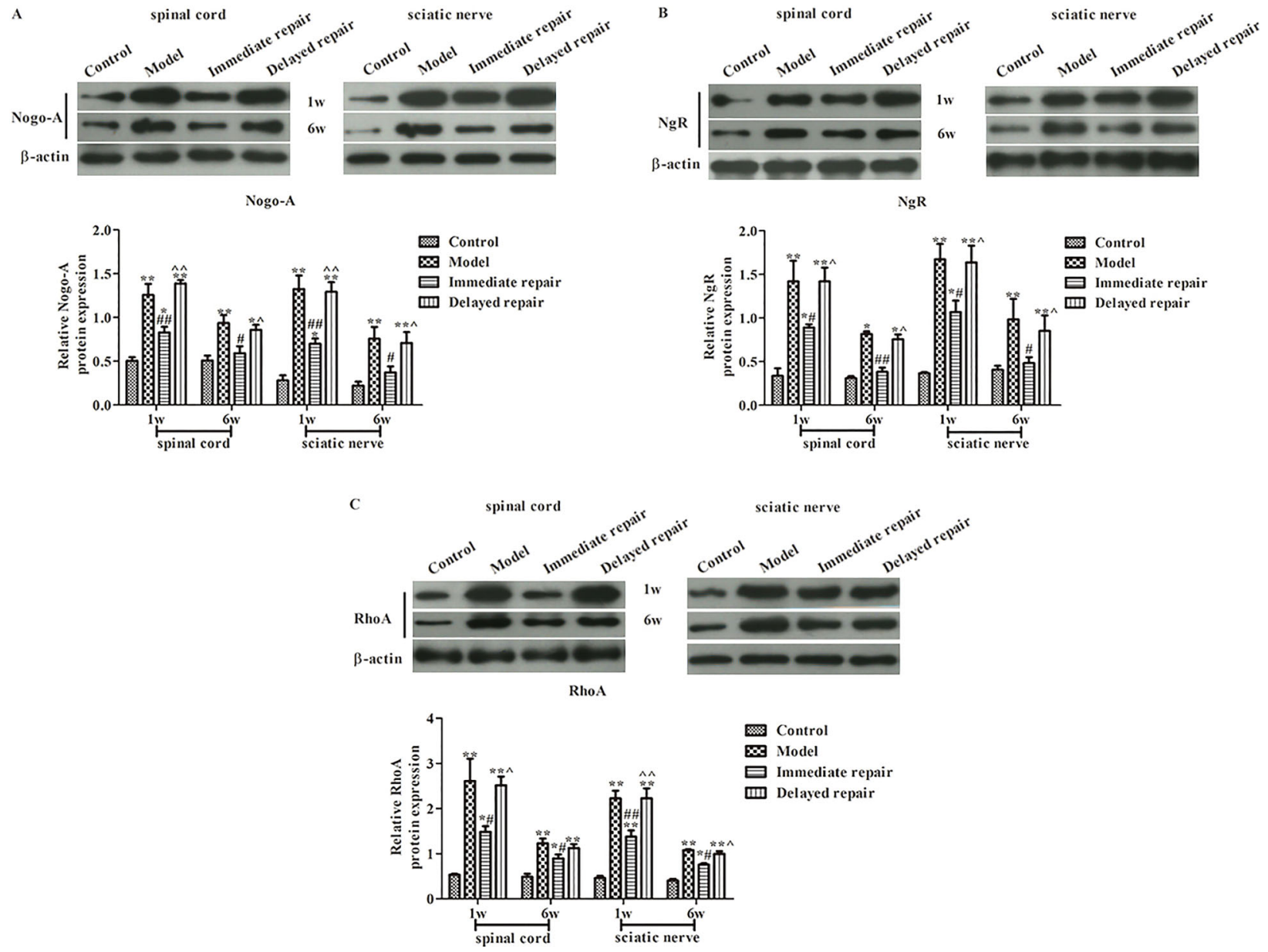

Figure 4. The expression of Nogo-A (A), $\mathrm{NgR}(\mathbf{B})$, and RhoA (C) protein was detected by western blot in rats after sciatic nerve injury. ${ }^{*} \mathrm{P}<0.05$, ${ }^{* *} \mathrm{P}<0.01$ compared with control group; ${ }^{\#} \mathrm{P}<0.05,{ }^{\#} \mathrm{P}<0.01$ compared with model group; ${ }^{\wedge} \mathrm{P}<0.05$, ${ }^{\wedge} \mathrm{P}<0.01$ compared with Immediate repair group. The data are reported as means \pm SD and were compared with ANOVA followed by LSD test.

nerve group were less, and the protein expressions of Nogo-A, NgR, and RhoA in the spinal cord and sciatic nerve tissues were decreased. RhoA is described in experimental models of sciatic nerve injury and central nervous system myelin exposure, indicating that the pharmacological blockers of RhoA block the function of Nogo-A $(23,24)$. Our study suggests that RhoA signal was a key regulator of Nogo-A in the repair of sciatic nerve injury. Inhibition of RhoA or Rho kinase downstream from C3 transferase promotes axonal growth and axonal regeneration after injury, which is related to a decrease of Nogo-A transcription level $(25,26)$. The regulation of Nogo-A expression by RhoA is closely related to axonal dynamics. Nogo-A restrains neuronal growth by negatively regulating the movement of the growth cone (27). Our study suggests that Nogo-A played a role in the inhibition of axon growth.

$\mathrm{NgR}$ is a common receptor for the three known myelin-associated inhibitors, Nogo-A, myelin-associated glycoprotein (MAG), and oligodendrocyte myelin glycoprotein (OMgp) (28). NgR plays a key role in the failure of axonal regeneration in the adult mammalian CNS (29). In previous studies, NgR antagonistic peptide NEP1-40, a soluble $\mathrm{NgR}$, and a transgenic $\mathrm{NgR}$ inhibitor with soluble function blocked NgR fragment NGR310 (30). NgR has been used to antagonize the binding of myelin-related inhibitors with $\mathrm{NgR}$, thus promoting axon regeneration and functional recovery after spinal cord injury $(31,32)$. The inhibitory effect of $\mathrm{NgR}$ on the growth of myelin sheath has also been demonstrated in vitro (33). In this study, the protein expression of $\mathrm{NgR}$ in spinal cord and sciatic nerve tissues decreased compared with the sciatic nerve transection group. These findings suggest that Nogo-A and its receptor had significant effects on the repair of sciatic nerve injury in rats.

However, our study had some limitations. A lack of research on relevant pathways evaluated in our experiments prevented the elucidation of specific mechanisms 
by which Nogo-A inhibited the repair of sciatic nerve injury in rats.

In conclusion, the expression of Nogo-A and its receptor increased after sciatic nerve injury, suggesting that Nogo-A and its receptor may play an inhibitory role in the repair process of sciatic nerve injury in rats. Future studies may further evaluate the expression of Nogo A at

\section{References}

1. Bonin RP. Running from pain: mechanisms of exercisemediated prevention of neuropathic pain. Pain 2015; 156: 1585-1586, doi: 10.1097/j.pain.0000000000000302.

2. Pan B, Huo T, Hu Y, Cao M, Bu X, Li Z, et al. Exendin-4 promotes Schwann cell proliferation and migration via activating the Jak-STAT pathway after peripheral nerve injury. Neuroscience 2020; 437: 1-10, doi: 10.1016/j.neuroscience.2020.04.017.

3. Chen YW, Li YT, Chen YC, Li ZY, Hung CH. Exercise training attenuates neuropathic pain and cytokine expression after chronic constriction injury of rat sciatic nerve. Anesth Analg 2012; 114: 1330-1337, doi: 10.1213/ANE.0b 013e31824c4ed4.

4. Akyuz G, Kenis O. Physical therapy modalities and rehabilitation techniques in the management of neuropathic pain. Am J Phys Med Rehabil 2014; 93: 253-259, doi: 10.1097/ PHM.0000000000000037.

5. Dworkin RH, O'Connor AB, Backonja M, Farrar JT, Finnerup NB, Jensen TS, et al. Pharmacologic management of neuropathic pain: evidence-based recommendations. Pain 2007; 132: 237-251, doi: 10.1016/j.pain.2007.08.033.

6. Almeida C, Maman DA, Kusuda R, Cadetti F, Ravanelli MI, Queiroz AL, et al. Exercise therapy normalizes BDNF upregulation and glial hyperactivity in a mouse model of neuropathic pain. Pain 2015; 156: 504-513, doi: $10.1097 /$ 01.j.pain.0000460339.23976.12.

7. Huber AB, Weinmann O, Brosamle C, Oertle T, Schwab ME. Patterns of Nogo mRNA and protein expression in the developing and adult rat and after CNS lesions. $J$ Neurosci 2002; 22: 3553-3567, doi: 10.1523/JNEUROSCI.22-0903553.2002

8. Mingorance-Le Meur A, Zheng B, Soriano E, del Rio JA. Involvement of the myelin-associated inhibitor Nogo-A in early cortical development and neuronal maturation. Cereb Cortex 2007; 17: 2375-2386, doi: 10.1093/cercor/bhl146.

9. Hunt D, Coffin RS, Prinjha RK, Campbell G, Anderson PN. Nogo-A expression in the intact and injured nervous system. Mol Cell Neurosci 2003; 24: 1083-1102, doi: 10.1016/j.mcn. 2003.09.002.

10. Cheatwood JL, Emerick AJ, Schwab ME, Kartje GL. Nogo-A expression after focal ischemic stroke in the adult rat. Stroke 2008; 39: 2091-2098, doi: 10.1161/STROKEAHA.107.50 7426.

11. Mingorance A, Fontana $X$, Solé $M$, Burgaya $F$, Urena JM, Teng FY, et al. Regulation of Nogo and Nogo receptor during the development of the entorhino-hippocampal pathway and after adult hippocampal lesions. Mol Cell Neurosci 2004; 26: 34-49, doi: 10.1016/j.mcn.2004.01.001.

12. Vajda F, Jordi N, Dalkara D, Joly S, Christ F, Tews B, et al. Cell type-specific Nogo-A gene ablation promotes axonal the gene level and study its effect on the repair of sciatic nerve injury.

\section{Acknowledgments}

This study was supported by the Key Research and Development Plan of Shandong Province (2018Gsf118026).

regeneration in the injured adult optic nerve. Cell Death Differ 2015; 22: 323-335, doi: 10.1038/cdd.2014.147.

13. Petrinovic MM, Duncan CS, Bourikas D, Weinman O, Montani L, Schroeter A, et al. Neuronal Nogo-A regulates neurite fasciculation, branching and extension in the developing nervous system. Development 2010; 137: 2539-2550, doi: 10.1242/dev.048371.

14. Petrinovic MM, Hourez R, Aloy EM, Dewarrat G, Gall D, Weinmann $\mathrm{O}$, et al. Neuronal Nogo-A negatively regulates dendritic morphology and synaptic transmission in the cerebellum. Proc Natl Acad Sci USA 2013; 110: 10831088, doi: 10.1073/pnas.1214255110.

15. Papadopoulos CM, Tsai SY, Cheatwood JL, Bollnow MR, Kolb BE, Schwab ME, et al. Dendritic plasticity in the adult rat following middle cerebral artery occlusion and Nogo-a neutralization. Cereb Cortex 2006; 16: 529-536, doi: 10.10 93/cercor/bhi132.

16. Cobianchi S, Marinelli S, Florenzano F, Pavone F, Luvisetto S. Short- but not long-lasting treadmill running reduces allodynia and improves functional recovery after peripheral nerve injury. Neuroscience 2010; 168: 273-287, doi: 10.1016/j.neuroscience.2010.03.035.

17. Groover AL, Ryals JM, Guilford BL, Wilson NM, Christianson JA, Wright DE. Exercise-mediated improvements in painful neuropathy associated with prediabetes in mice. Pain 2013; 154: 2658-2667, doi: 10.1016/j.pain.2013.07. 052.

18. Ma CHE, Takao O, Cobos EJ, Latrémolière A, Ghasemlou $\mathrm{N}$, Brenner GJ, et al. Accelerating axonal growth promotes motor recovery after peripheral nerve injury in mice. J Clin Investig 2011; 121: 4332-4347, doi: 10.1172/JCI58675.

19. Li L, Li Y, Fan Z, Wang X, Li Z, Wen J, et al. Ascorbic acid facilitates neural regeneration after sciatic nerve crush injury. Front Cell Neurosci 2019; 13: 108, doi: 10.3389/fncel.2019. 00108.

20. Pradhan AD, Case AM, Farrer RG, Tsai SY, Cheatwood JL, Martin JL, et al. Dendritic spine alterations in neocortical pyramidal neurons following postnatal neuronal Nogo-A knockdown. Dev Neurosci 2010; 32: 313-320, doi: 10.1159/ 000309135.

21. Delekate A, Zagrebelsky M, Kramer S, Schwab ME, Korte M. NogoA restricts synaptic plasticity in the adult hippocampus on a fast time scale. Proc Natl Acad Sci USA 2011; 108: 2569-2574, doi: 10.1073/pnas.1013322108.

22. Aloy EM, Weinmann O, Pot C, Kasper H, Dodd DA, Rulicke T, et al. Synaptic destabilization by neuronal Nogo-a. Brain Cell Biol 2006; 35: 137-156, doi: 10.1007/s11068-007-90 14-3.

23. Liu YY, Jin WL, Liu HL, Ju G. Electron microscopic localization of Nogo-A at the postsynaptic active zone of 
the rat. Neurosci Lett 2003; 346: 153-156, doi: 10.1016/ S0304-3940(03)00508-1.

24. Schwab ME. Functions of Nogo proteins and their receptors in the nervous system. Nat Rev Neurosci 2010; 11: 799811, doi: 10.1038/nrn2936.

25. Fournier AE, GrandPre T, Strittmatter SM. Identification of a receptor mediating Nogo-66 inhibition of axonal regeneration. Nature 2001; 409: 341-346, doi: 10.1038/35053072.

26. Wang KC, Kim JA, Sivasankaran R, Segal R, He Z. P75 interacts with the Nogo receptor as a co-receptor for Nogo, MAG and OMgp. Nature 2002; 420: 74-78, doi: 10.1038/ nature01176.

27. Mi S, Lee X, Shao Z, Thill G, Ji B, Relton J, et al. LINGO-1 is a component of the Nogo-66 receptor/p75 signaling complex. Nat Neurosci 2004; 7: 221-228, doi: 10.1038/nn1188.

28. Shao Z, Browning JL, Lee X, Scott ML, Shulga-Morskaya S, Allaire $\mathrm{N}$, et al. MiTAJ/TROY, an orphan TNF receptor family member, binds Nogo-66 receptor 1 and regulates axonal regeneration. Neuron 2005; 45: 353-359, doi: 10.1016/ j.neuron.2004.12.050.

29. Brann $A B$, Tcherpakov $M$, Williams $I M$, Futerman $A H$, Fainzilber M. Nerve growth factor-induced p75-mediated death of cultured hippocampal neurons is age-dependent and transduced through ceramide generated by neutral sphingomyelinase. J Biol Chem 2002; 277: 9812-9818, doi: 10.1074/jbc.M109862200.

30. Karnezis T, Mandemakers W, McQualter JL, Zheng B, Ho PP, Jordan KA, et al. The neurite outgrowth inhibitor Nogo $A$ is involved in autoimmune-mediated demyelination. Nat Neurosci 2004; 7: 736-744, doi: 10.1038/nn1261.

31. Bros-Facer V, Krull D, Taylor A, Dick JRT, Bates SA, Cleveland $M S$, et al. Treatment with an antibody directed against Nogo-A delays disease progression in the SOD1G93A mouse model of Amyotrophic lateral sclerosis. Hum Mol Genet 2014; 23: 4187-4200, doi: 10.1093/hmg/ddu136.

32. Oertle $T$, van der Haar ME, Bandtlow CE, Robeva A, Burfeind $P$, Buss A, et al. Nogo-A inhibits neurite outgrowth and cell spreading with three discrete regions. J Neurosci 2003; 23: 5393-5406, doi: 10.1523/JNEUROSCI.23-1305393.2003.

33. Joset A, Dodd DA, Halegoua S, Schwab ME. Pinchergenerated Nogo-A endosomes mediate growth cone collapse and retrograde signaling. J Cell Biol 2010; 188: 271-285, doi: 10.1083/jcb.200906089. 